\title{
Flying Music Teaching Idea, Building up an Adaptive and Accommodative Way of Teaching - Running toward Freedom
}

\author{
Jing Sun \\ Academy of Music \\ Langfang Normal College \\ Langfang, China
}

\begin{abstract}
The flying music teaching idea changes the traditional teaching mode and activates students' music thinking in an open education mode. In the classroom teaching, it changes the "image of teacher", and uses the classroom form with students as main body, and encourages students' behavior and performance. In this new innovative music teaching mode, music education becomes the base of students' aesthetic activities and creation activities. Music class really becomes a factory to inspire and develop students' creative ability. We can achieve the ultimate goal of the development of music education.
\end{abstract}

Keywords-flying; music teaching idea; build up; adaptive; accommodative

\section{INTRODUCTION}

Music is a rich, charming and challenging subject for human beings. Music learning provides students with a unique wisdom, open up the vision of the students, and cultivate their everlasting innovative thinking, and provide an opportunity for the development of life. In recent years, the world and China pay more and more attention to the function of music education from children to adults, from primary school to higher education. Music teaching with its unique characteristics is a course that we can not overlook in the cultivation of innovative talents in our country. To play the function of music education, we also need to reform the traditional teaching ideas boldly, and fly teaching ideas and free education, so that we can really cultivate talents with literacy and innovative spirit. Below the author will describe it through three aspects, how to change the traditional teaching ideas, how to fly teaching ideas and how to free music education.

\section{LEARNING TO "POCKETING PRIDE" AND CHANGING} THE Class Position OF "THE TEACHER AND THE STUDENT"

At present, due to various factors music teaching reform is not ideal. In many towns and cities, teachers still use the former Soviet Union Kairov's education system and teaching idea with "teacher, book and class" as center in the music class teaching activities. This is a traditional music teaching mode that teachers teach students on the teacher's desk and students learn below. Such teaching mode makes students passive, mechanized and submissive in learning, results in the serious lack of individuality and subjectivity of students, and severely curbs students' imagination and creativity. Traditional classroom teaching mode, from superficial aspect, kills students' music potential and growth ability; from the in-depth aspect, it deviates the real meaning and connotation of music education. Many students have a wealth of cultural and technical knowledge, but they lack in-depth thinking in many aspects. The students think to study hard is for high official positions and riches. The cognition has resulted in a lot of negative events in the past ten years. Thus, as we have engaged in music teaching, shall we reflect ourselves, learn to pocket pride, and do some simple things in a down-toearth way. Seen from this, the author thinks it can really play the function of music, help students open their heart and enable students to grow into a pillar of the state with healthy mind by changing the class position of "teacher" and "student" and shortening the hear-to-heart distance between teachers and students.

Case 1: The music teaching method class in normal college- the first article (Understanding of Music and Education) "Fig. 1"

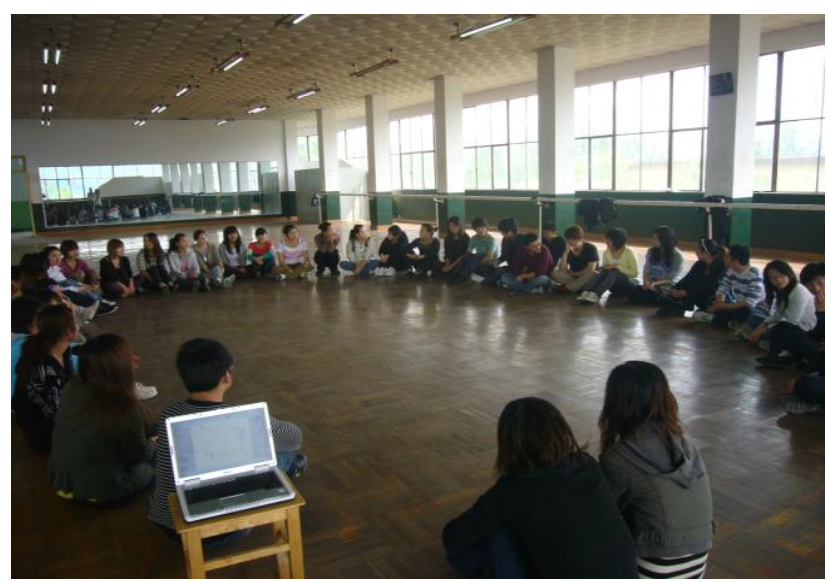

Fig. 1. 
Teaching environment: The first class of the music teaching method was selected in the dance classroom.

Traditional teaching position: Students stood in three rows, like the form of sports or dance class. I stood alone on the opposite side of the three rows of students.

Teachers and students' behavior and inner performance: students looked tired and passive, had no expectation and lack excitement for first music teaching method class. There was a strong strange feeling during our first meeting.

Changing the teaching position: let student sit in a circle together with me.

Teachers and students' behavior and inner performance after changing the class mode: students actively sat in a large circle. They looked extremely exciting. Previously they felt strange even feared, but this time they took my hand and sat down naturally and affectionately. When I asked the students their feelings, they said it was the first time that they felt teacher as a friend, kind and warm, rather than high above. They had a desire to follow the lead of the teacher, and an initiative to participate in the class. They though actively, and were willingness to communicate with the teacher.

Conclusions: in the first music teaching method class, under the condition of same teaching environment, take the seating manner of sitting in a circle in class. It breaks the traditional position of teacher and students and let students experience changes of their mood. Tell students the upcoming way of a teacher with experimental method of experiencing changes of mood personally. A teacher can narrow the gap with students as long as he/she learn to pocket his/her pride. This is main content of my first teaching method class. With a good teaching method, teacher shall first shorten the distance with students and integrate into group of students. Along with the light music of Spring Song (the work of Mendelssohn) and The Elixir of Love (the work of Donizetti), students taught freely with me, and they understood the connotation of "sound", "music", "teaching" and "education" and the meaning and value of the teaching method class. In the specific class environment, I saw students' long-lost single-minded eyes and proactive state in "listening", "thinking" and "answering".

\section{CREating the "OPEN" Music Teaching Mode to LEAD STUDENTS TO FIND LIFE ELEMENTS IN MUSIC}

For more than half a century, German Orff's teaching method and Hungarian Kodaly's teaching method, the Japanese SUZUKI teaching method and American DBME teaching method and a lot of well-known music teaching methods have been established one after another and popularized in our country. These teaching methods pay much attention to students' main body status, pay attention to the use of modern teaching methods in teaching, emphasize to strengthen music experience by participating in music activities, to develop students' music potential through the creative teaching, and emphasize that teaching shall be based on stimulating students' interests and developing their good altitude. These excellent teaching methods were all grown up in their national conditions. Their one-sidedness is self- evident when introduced in our teaching. Therefore, we shall use them selectively, boldly pave a way adapting to our national conditions and create an open music teaching mode. In this way, we can really fly students' music thinking, build their innovative quality and let students experience charm of music personally.

\section{Case 2: Music of stone (work song) "Fig. 2", "Fig. 3"}

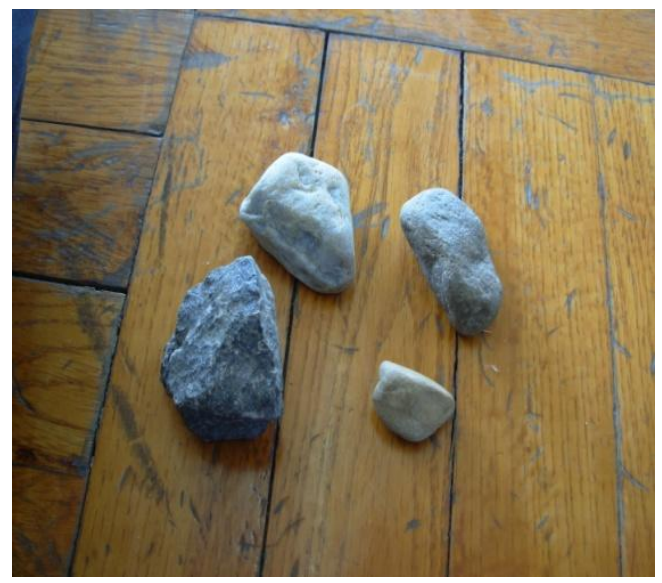

Fig. 2.

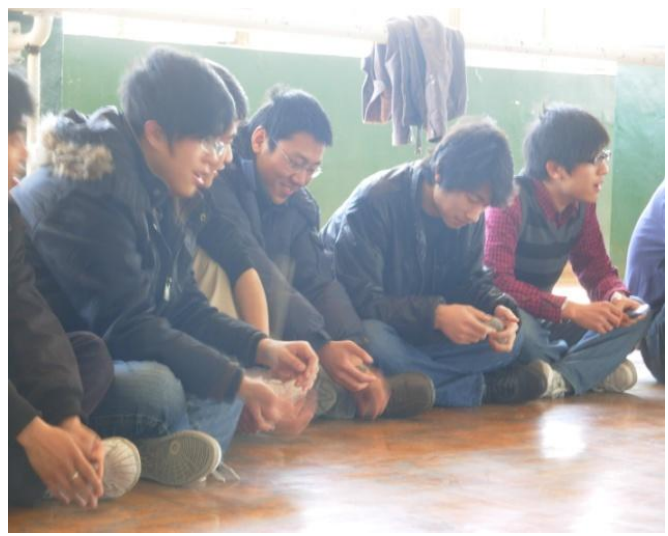

Fig. 3.

This is one music class about "stones" - work song. I imitated the work rhythm by striking stones. In singing, simply used work mimetic words "Hai Yo" to create a labor scene. Took this opportunity to broaden students' understanding of the music - everything of our life is the expression of music and sincere performance of music. The open music teaching mode is applied in this class in four aspects:

- Arranged students to prepare two stones before class, but not told them the role of "stones" in next class. It might arouse students' incredible expectation and to think what's the relationship of stone and music, and helped them look forward to new class.

- Asked students to site around the floor. At first I taught students to use two stones in their hands with slow motions, and demonstrated how to strike the stone. Students learned from unskilled to skilled, and 
felt the change of speed and the regular rhythm of the collective work. When they felt a bit tired, I added the work song of "Hai Yo". Students experienced this simple melody along with work song and felt the change along with music. Everyone forgot tiredness and was motivated. After the experience, I told students the music they played in this environment was work song, and I asked them to summarize the characteristics of this work song.

- Asked students to divide into two groups and to set up a labor scene by discussion. They could create and compile a work song with stones or any objects that could make sound or use a variety of sound means to make sounds. Told students that music is a language, and it could be used for exchange interaction and collision.

- The purpose of this class is to explain students what is work song and let students know the characteristics of this music. In class, I didn't explain the definition and characteristics of "work song" traditionally, but I led students to create a labor scene and stimulated them to participate actively, and guided and enlightened them to observe and think and then summarize and helped them find charm of music in life. I told students to love life and love music, and then our life would be colorful. It is our primary task to let students know the true meaning of music and life with the "open" teaching mode and concept.

\section{InNOVATING TEACHING STRATEGIES ACCORDING TO Music TeXt And LetTing Students Become the MASTER OF THE CLASS}

In music teaching, we should emphasize modern education ideas, such as people orientation, stimulating learners' initiative and respecting learners' subjectivity and personality development, to let students become the master of class. ${ }^{(1)}$ In primary and secondary schools, music course is one of most active and practical courses. Therefore, music teaching should not be rational and academic, but of living and colorized. Teachers should develop students' discovery eyes through colorful music activities, and stimulate their active participation enthusiasm. Help students perceive from experience and think in the perception, and obtain knowledge from thinking, absorb the music culture and improve music skills quietly and silently.

Even when students talk about the learning of music theory with such charm, they think that music theory learning, as the other theory courses, is boring. In fact, this is mainly because of fixed and old concepts of teachers in class teaching. They break away from the lively characteristics of music in teaching music theory. In order to illustrate the idea, I designed a class with "Canon" as example in my music teaching method class to open up music teachers' eyes and warn them not to break away from the self characteristics of music in any music class.

\footnotetext{
(1) Zeng Qi \& Du Lei. Analysis on Local Adaptability of Participatory Learning. Education Theory and Practice, 2005-08.
}

Case 3: Canon (Do not give the scores of former two stages and give the score of third stage) "Fig. 4"

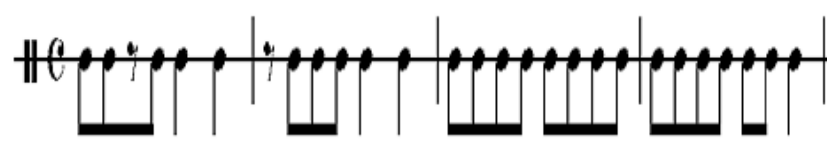

什么 是卡农? 这就是 卡 农. 一个小组先开始, 另一个组再进来

Fig. 4.

First, I have changed the traditional way of explanation according to the textbook and designed a rap teaching activity with fixed rhythm. I divide the case into three stages and use them to explain music theory through "Canon".

Three steps in first stage:

- Let training teachers sing the tune of "What is Canon?" in a quiet environment.

- Let them stand up and sing again with their feet stepping, and feel the difference of music in a dynamic state.

- During stepping and singing, I let them add the rhythm of clap as accompanied sound to experience this music further.

Three steps in the second stages:

- Let them sing "What is Canon?" three times in a rap way in different style along with stepping. First time, use stepping and rap; second time, use stepping and rap and clapping; third time, eliminate rap and only use stepping with clapping until the end of music.

- Divide students into two groups. The other group enters into the rap of "What is Canon?" after the first group enters the second section. Each group performs according to requirements of first step in the second stage. Everyone has entered into the music style of the characteristics of Canon imperceptibly after this step.

- Regroup students and divide them into three groups. The method is the same as that of the second step.

The design purpose of the teaching strategy of the first two steps: first, think the rap music of "What is Canon?"; second, divide into two or three parts and let them perform together and stimulate students to think about the characteristics of Canon.

Two steps in the third stage:

- Based on the rap rhythm of "What is Canon?", let them give a impromptu tune and sing with "la", "du", "br" and other syllables with the tune.

- Divide into two groups according to the requirements of second step in second stage. In addition, make design on formation pattern, ictus and pianissimo, and the change of speed. 
The design purpose of teaching strategy of the third step: give rhythmical color to the music of "Canon", and give learners a strong feeling of freshness in learning music theory, and help them dedicate to the experience with greatest enthusiasm.

Effects: Learners did not feel tired in the 50-minute class and they experienced and learned in a happy mood. With such interactive teaching method, learners not only grasped the knowledge points of "Canon" in this class, but also improved their ability of music listening, sensing and acting.

Thus, interest is the driving force of learning. The interestingness is the flint to light interests. The innovative teaching strategy design is a magic weapon to arouse students' learning enthusiasm. Only in this way can it arouse students' spirit of inquiry in the study. Of course, some students may encounter setbacks in the course. At this time, teachers should give them encouragement in time, and help them keep on. At this point, teachers should teach students that in the study, it is worth the challenge!

The International Music Education Association (ISME) believes that music education can effectively develop individual potential, stimulate the creation of impulse, sublimate spiritual realm, and improve the quality of life. The diversification of world music has brought opportunities for international understanding, cooperation and peace. "National Art Education Standards" of the United States deems that: "music education can cultivate an integrated man. It has a unique role in the development of individual intuition, reasoning, imagination and expression and communication ability. Music art is the enrichment of human culture and the crystallization of human civilization. Music art has injected a lot of passion into the learning of other disciplines. Education without music art is not complete. Music art itself is a strong economic power. The future society depends on the construction of vibrant art society" (2). For this great goal, music educator shall fly the music teaching ideas with our heart and explore the way of music teaching adapting to our national conditions and free the music education.

\section{REFERENCES}

[1] Franz Niermann\&Constanze Wimmer. Musiklernrn-ein Lebenlang. 2004 by Universal Edition.

[2] Dewey John. Thinking and Experience on Education. People's Publishing House, 1991.

[3] Wang Anguo, editor in chief. From Practice to Policy - The Reform and Development of Music Education in Our Country. Huacheng Publishing House, Jan. 2005.

[4] Revised by the Ministry of Education of the People's Republic of China. Music Curriculum Standards. Beijing Normal University press, 2006 Edition

[5] Tu Yanguo. Running toward Freedom - Study on the Development of Education and People. Huazhong Normal University Press, 1999-08.

[6] Edited by Xie Jiaxing\&Yu Wenwu. Music Education and Teaching Method. Higher Education Press, 2006.

[7] Zhao Jianping. The Cultivation of Creative Thinking in Music Practice Activity, April 2005.

\footnotetext{
(2) Liu Pei. Music Standards of NBPTS, 2003-05.
}

[8] Yu Bing. Discussion on the Importance of Music in School Education, Chinese Music Education, May 2006 